\title{
Shell Shape Analysis and Spatial Allometry Patterns of Manila Clam (Ruditapes philippinarum) in a Mesotidal Coastal Lagoon
}

\author{
Nathalie Caill-Milly, ${ }^{1}$ Noëlle Bru, ${ }^{2}$ Kélig Mahé, ${ }^{3}$ Catherine Borie, ${ }^{1}$ and Frank D’Amico ${ }^{4}$ \\ ${ }^{1}$ Laboratoire Ressources Halieutiques Aquitaine, IFREMER, FED 4155 MIRA, 1 allée du Parc Montaury, 64600 Anglet, France \\ ${ }^{2}$ Laboratoire de Mathématiques et de leurs Applications de Pau, UMR CNRS 5142, FED 4155 MIRA, \\ UNIV PAU \& PAYS ADOUR, 64000 Pau, France \\ ${ }^{3}$ Pôle de Sclérochronologie, IFREMER Centre Manche-Mer du Nord, 150 Quai Gambetta, 62200 Boulogne-sur-Mer, France \\ ${ }^{4}$ UMR ECOBIOP, FED 4155 MIRA, UNIV PAU \& PAYS ADOUR, Campus Montaury, 64600 Anglet, France
}

Correspondence should be addressed to Nathalie Caill-Milly, nathalie.caill.milly@ifremer.fr

Received 19 April 2012; Accepted 25 June 2012

Academic Editor: Robert A. Patzner

Copyright ( 2012 Nathalie Caill-Milly et al. This is an open access article distributed under the Creative Commons Attribution License, which permits unrestricted use, distribution, and reproduction in any medium, provided the original work is properly cited.

\begin{abstract}
While gradual allometric changes of shells are intrinsically driven by genotype, morphometrical shifts can also be modulated by local environmental conditions. Consequently the common use of a unique dimension (usually length) to assess bivalves' growth may mask phenotypic differences in valve shape among populations. A morphometric exhaustive study was conducted on Manila clam, Ruditapes philippinarum, by acquiring data in the French Arcachon Bay (intrasite phenotypic variability) and by comparing with other sites in the literature (intersite phenotypic variability). 2070 shells were subsampled, weighted, and automatically measured using TNPC software. Some ratios' values indicate a relatively round and globular shape shell in comparison with other sites confirming poor conditions for some individuals. Among adult clams, three main morphological groups were identified and discussed according to spatial considerations. Allometric relations for pairs of shell descriptors were determined by testing classical linear and piecewise regression models on log-transformed relation of Huxley. A significant shape change correlated to size was observed; it corresponds to the second year of life of the clam. Relationships between density, disease, and shell shape are demonstrated and discussed related to other potential factors affecting shell shape. Finally, consequences on population regulation are addressed.
\end{abstract}

\section{Introduction}

Growth of individuals is commonly assessed by correlating the evolution of the largest dimension of the individuals along time. For bivalves, this dimension can be the valve's length as for cockle, clam, mussel, razor shell, the valve's height as for oyster, scallop [1]. The shape changes of the shell are induced by the differential growth vectors operating at distinct locations around the mantle edge [2], organ that plays a key role in the shell secretion. This highlights the need of taking into account several allometric ratios.

Those gradual allometric changes are clearly driven by genotype and occur during ontogeny; they are usually associated with the conservation concept of physiological favorable surface area to volume ratios [1]. At the same time, those morphometrical shifts can also be modulated by local environmental conditions [3-12].
So, the convenient approach which consists in considering growth through a unique dimension can mask phenotypic plasticity responses in valve shape. While bivalves allocate a significant portion of their total energy budget to shell growth [13], apparent disparities concerning length could occur among individuals even if they dedicate the same amount of energy to shell growth. Shell increments could indeed shift to other dimensions such as height, width, and thickness of the valve. This concern is important because it gives new arguments to suggest that deficient growth in length is not always due to problems of energy input deficit (e.g., phytoplankton) but could also be related to intrinsic considerations leading to specific morphological patterns.

In order to investigate the question of growth in the fullest possible way for ecological and commercial purposes, an exhaustive morphometric study is proposed by acquiring data in Arcachon Bay (intrasite phenotypic variability) and 


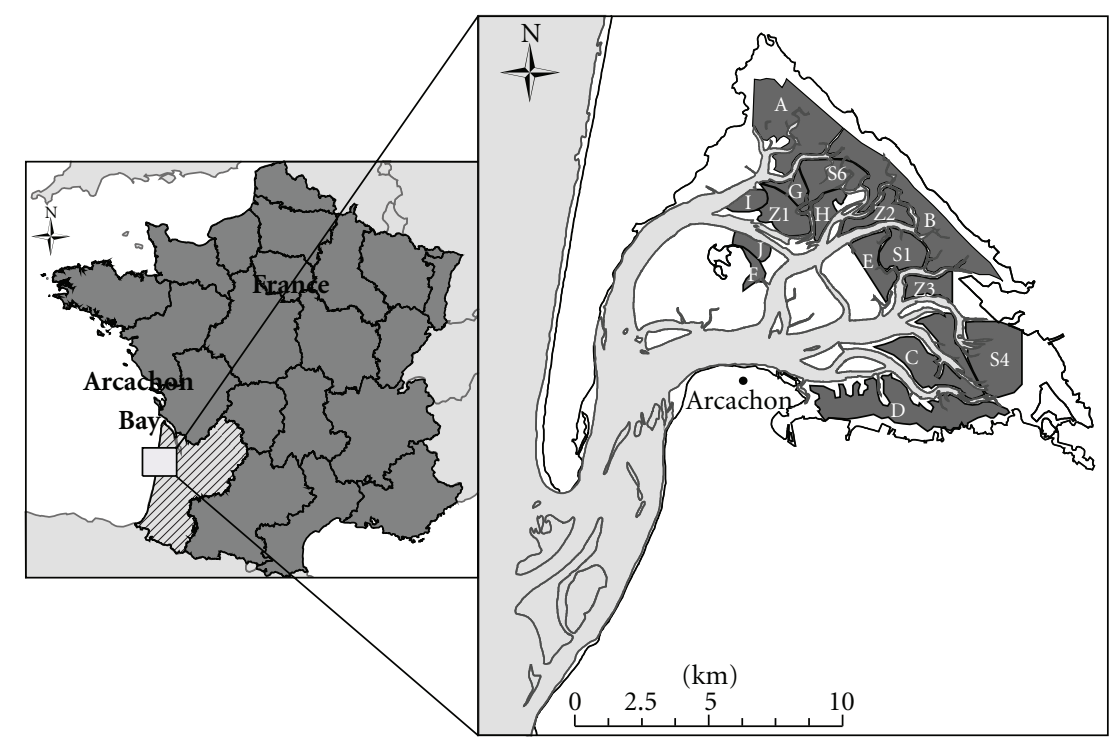

FIGURE 1: Maps showing the studied site Arcachon Bay (France) and localization of the sampled strata (Sources: ESRI, BD Carthage, Ifremer-M. Lissardy).

by comparing with other sites in the literature (intersite phenotypic variability). The chosen biological model is Manila clam, Ruditapes philippinarum (Adams and Reeve, 1850) which supports an important commercial fishing activity with around 550 to 1.000 tons per year for the Arcachon Bay located in the southwest coast of France, hoisting it at the first rank of French production sites.

Various ecological factors are identified for their effect on bivalve shell shape: wave impact, trophic conditions, water depth, density... [2, 14]. In this study, we decided to focus on two factors integrating a populational dimension and be susceptible to influence the growth and the shell shape: density and brown muscle disease-emerging pathology. Several studies have already been conducted on density dependence of the Manila clam's shell shape but without consensus [1518]. One of the supposed effects is that the dorso-ventral shell axis (height) should be the most affected by space competition since buried clams present their anteroposterior axis (length) almost perpendicular to the substrat [18]. Concerning pathology, we considered it challenging to study relationships between the prevalence of BMD affection which is known for having negative impact on the functioning of the adductor muscles involved in the shell's closure [19] and shell shape. Those features were preferred to other potential factors such as perkinsosis or brown ring disease since their low impacts on the Arcachon Bay population were demonstrated [20]. For other environmental modulators, (such as type of sediment, shore level, etc) data at sufficient fine scale are not currently defined.

\section{Materials and Methods}

2.1. Study Site. Arcachon Bay is a $156 \mathrm{~km}^{2}$ semi sheltered lagoon in the southwest coast of France (Figure 1). Mostly composed of tidal flats $\left(110 \mathrm{~km}^{2}\right.$ within the inner lagoon); this mesotidal system is characterized by a sediment composition ranging from mud to muddy sands and colonized by vast Zostera noltii seagrass meadows. Both influenced by external neritic waters and by continental inputs [20], this bay presents a semidiurnal macrotidal rhythm. Temperature and salinity gradients within the bay are controlled by the characteristics of these water masses as well as the slow renewal of water by tides [21]. With an average salinity of 30 (source Archyd network) which is higher than freshwater salinity and lower than seawater one's, the investigated area is considered as brackish water [22].

2.2. Origin of the Data. R. philippinarum shells were collected in Arcachon Bay during the last biomass survey in 2010 . Henceforth biennial, this field survey is carried out with a standardised protocol (stratified random sampling) with 14 strata located at intertidal level (excluding channels) investigated for a total of 490 sampling stations. Sediments, core of $0.25 \mathrm{~m}^{2}(0.5 \mathrm{~m} \times 0.5 \mathrm{~m})$ on a $0.2 \mathrm{~m}$ depth, were sampled with a Hamon grab at the high tide and filtered onboard with running water over a set of three sieves with 2,1 , and $0.5 \mathrm{~cm}$ mesh sizes. On the whole collected shells, 2070 shells were randomly subsampled.

\subsection{Shells Preparation and Morphology Descriptors of Individ-} uals. In laboratory, all the shells were first cleaned and dried at $38^{\circ} \mathrm{C}$ for $48 \mathrm{~h}$. Then, the valves were separated and analyses on two high-resolution pictures (lateral and ventral views) were performed with the TNPC software (Digital Processing for Calcified Structures, http://www.TNPC.fr) on left valve. To describe the morphology of the individuals, seven classical parameters were retained:

(i) length $(L)$, defined as the longest distance from front edge to back edge $(\mathrm{mm})$. It is the reference length obtained from lateral view; 
TABLE 1: Morphometric variables for arcachon bay.

\begin{tabular}{|c|c|c|c|c|c|}
\hline Descriptor & Formulae & Minimum & Maximum & Mean & Ecart-type \\
\hline Elongation index & $=H / L$ & 0.66 & 0.86 & 0.75 & 0.02 \\
\hline Compacity index & $=W / L$ & 0.19 & 0.38 & 0.28 & 0.02 \\
\hline Convexity index & $=W / H$ & 0.35 & 0.51 & 0.37 & 0.03 \\
\hline Circle index lateral view & $=\mathrm{AL} / 0.25 \times L^{2} \times \pi$ & 0.65 & 0.85 & 0.73 & 0.02 \\
\hline Circle index ventral view & $=2 \times \mathrm{AV} / 0.25 \times$ LVent $^{2} \times \pi$ & 0.36 & 0.70 & 0.48 & 0.04 \\
\hline Reference Ellipse index lateral view & $=\mathrm{AL} / 0.25 \times L^{2} \times \pi$ & 2.63 & 3.43 & 2.94 & 0.10 \\
\hline Reference Ellipse index ventral view & $=2 \times \mathrm{AV} / 0.25 \times$ LVent $^{2} \times \pi$ & 0.73 & 1.40 & 0.95 & 0.08 \\
\hline Weight ratio 1 & $=S M / L$ & 0.06 & 1.76 & 0.57 & 0.27 \\
\hline Weight ratio 2 & $=S M / H$ & 0.08 & 2.17 & 0.76 & 0.35 \\
\hline Weight ratio 3 & $=S M / W$ & 0.23 & 5.80 & 2.02 & 0.88 \\
\hline
\end{tabular}

(ii) ventral length (LVent), as the longest distance from front edge to back edge ( $\mathrm{mm}$ ). It is the reference length obtained from ventral view;

(iii) height $(H)$, as distance from the umbo to edge $(\mathrm{mm})$. It is obtained from lateral view;

(iv) width $(W)$, as the longest distance of the valve in a lateral plane across the valve $(\mathrm{mm})$. It is obtained from ventral view;

(v) weight or shell mass (SM), as dry mass of the left valve $(\mathrm{mg})$;

(vi) area lateral $(\mathrm{AL})$, as area of the left valve projection $\left(\mathrm{mm}^{2}\right)$ from lateral view;

(vii) area ventral (AV), as area of the left valve projection $\left(\mathrm{mm}^{2}\right)$ from ventral view.

These seven parameters consist in linear or surface measures directly obtained from the shape analysis (lateral or ventral views) and weight measure of each left valve. Respective accuracies of almost $1.10^{-3}$ millimeter and $0.1 \mathrm{mg}$ are associated to linear and weight measures. Taken separately, those parameters do not allow describing the shell morphology because of a size effect. So not only to characterize the general morphology tendencies at the bay and at the strata scales, but also to examine allometric patterns for this population, 10 shape descriptors were defined from these parameters (Table 1). Such indices are supposed to give synthetic information on growth [23].

(i) Elongation index, Compactness index, and Convexity index to consider the coupled ratios between the 3 dimensions of the valve: a compact and convex bivalve has its width greater than $50 \%$ of its height which means a Convexity index greater than 0.5 [24];

(ii) Circle index lateral view (CIL) and Circle index ventral view (CIV) to compare the valves' forms to circular ones: the first one is the area of the valve (lateral view) related to the surface of a circle with $L$ as diameter. The second one is twice the area of the valve (ventral view) related to the surface of a circle with LVent as diameter. Those two indices are complementary, respectively, to Elongation and Compactness index. For both of them, if the value is close to 1, it means that the shape tends to be circular.

(iii) Ellipse index lateral view (EIL) and Ellipse index ventral view (EIV) are also considered to compare the valves' forms with elliptical ones. The first one is the area of the valve (lateral view) related to the surface of an ellipse with $L$ and $0.5 L$ as diagonals. The second one is twice the area of the valve (ventral view) related to the surface of an ellipse with LVent and 0.5 LVent as diagonals. Those indices are also complementary to Elongation and Compactness indices since they provide information on the more or less flattened form of the shell.

(iv) Three descriptors involving the weight and successively the 3 dimensions $(L, H$, and $W$ ) with weight ratio 1 , weight ratio 2 , and weight ratio 3 .

For Ruditapes philippinarum, globularity is described as a result of a faster increase of width related to length [7]. In terms of indices retained above, this character can be defined for clams presenting high Compactness, CIV, and EIV indices.

According to Hamai [25], Ohba [3], and Eagar et al. [9], morphometric characteristics could reveal more or less favorable environmental conditions. For Manila clam, a low Elongation index is observed to localities presenting clams with high condition index [23] meaning favorable environmental conditions. Consequently, CIL index close to 1 and EIL index greater than 1 could indicate unfavorable environmental conditions.

Moreover, Watanabe and Katayama [23] linked those morphometrics characteristics to commercial considerations for Ruditapes philippinarum: the less palatable individuals are 
the ones with fatter and rounder shell shape that is, high value of Elongation index and CIL index close to 1.

In other words, the best shape for ecological and economical purposes needs to be considered as a combination of several characteristics: at least low $H / L$ ratio combined with low values of CIL and EIL.

\subsection{Multivariate Analysis}

2.4.1. Shell Shape Analysis. In this subsection, all samples were considered. After brief descriptive statistics, linear regressions were performed on the logarithmically transformed data on parameters and shape descriptors versus size. It allows to account for significant shape changes correlated to size and is based on the classical equations for allometry $\left(Y=a X^{k}\right)$ proposed by Huxley [26]. Focusing on the coefficient named $k$ (allometric exponent) provides information about differences of growth rates between the two considered descriptors, in particular when it concerns width versus length it can reflect globularity as defined above. This parameter allows summarizing the growth rate and so it is compared to other areas.

When problems of "bad fitting" (presence of a shift between observed and predicted data) were detected using for example the corresponding residuals of this classical model, an alternative model built on piecewise regressions [27] was tested. It is also called segmented regressions model. It provides regression analysis on both sides of an automatically determined breakpoint. This methodology was used by Katsanevakis et al. [28] for bivalves' species. The choice of the "best" model was undertaken by using the AIC (Akaike Information Criterion; [29]) score; the lowest AIC score gives the one to select. The breakpoint is a parameter which can be viewed as an indicator of fast ecological changes or linked to marked events [28]. The regression equations before and after this breakpoint illustrate the shift of the shell growth to different morphological patterns during ontogeny.

2.4.2. Spatial Allometry Patterns. In this part, clams longer than $30 \mathrm{~mm}$ (i.e., 661 clams) were retained to consider spatial variability of allometric descriptors. This choice was decided in order to avoid size effect and to consider whether a link with two of the shape potential drivers (density or the brown muscle disease-coded BMD) could be detectable (since the smallest clam presenting this pathology was $26 \mathrm{~mm}$ long). To interpret the allometric variability in terms of density, two classes were defined: below 100 clams $\mathrm{m}^{-2}$ ("low density"); above 100 clams $\mathrm{m}^{-2}$ ("high density"). Concerning pathology, proportion of clams infected by BMD within the sample was coded into 3 classes: no clams infected ("No BMD"); below 3.7\% of infected clams ("Low BMD"); above $3.7 \%$ of infected clams ("High BMD"). Normalized principal components analysis (NPCA) was conducted in order to consider the relations between the synthetic shape descriptors and spatial considerations (strata encoded by letters, see Figure 1), density and proportion of clams infected by BMD (added as supplementary factors). This methodology is widely used for such investigations $[30,31]$.
Calculations were carried out under R (http://cran.r-project.org/web/packages/Rcmdr/index.html) and the following packages: factomineR for NPCA, stats for linear regressions, and SiZer for piecewise regressions (http://cran.r-project .org/web/packages/SiZer/index.html; [32]).

\section{Results}

3.1. Shell Shape in Arcachon Bay. The range of studied population length was between 10.4 and $45.0 \mathrm{~mm}$ (mean: $27.4 \mathrm{~mm}$; standard deviation: $5.21 \mathrm{~mm}$ ). Other statistics on the morphometric variables are summarized in Table 1. The mean shell pattern (average values) was described by an Elongation index of 0.75, a Compactness index of 0.28 , and a Convexity index of 0.37 . By comparison with traditional forms (circular or elliptical), valve shape was better described as circular when it was seen from the side view and elliptical when seen from ventral view. For the three weight ratios, the values were ranging between 0.57 and 2.02 and presented higher variability within the considered population than the other morphometric variables (relative standard deviations around $45 \%)$.

3.2. Allometric Patterns. Classical linear regressions (Figures 2(a)-2(g); see also Supplementary Materials available online at doi: 10.1155/2012/281206) revealed isometry for pattern such $H$ related to $L$ (called $H$ to $L$ allometric relation), characterized by an allometric exponent $(k)$ equal to 1.00 indicating that an increase of the length did not induce changes of growth rate of the height. For other ( $W$ versus $L, H$ versus $L, S M$ versus $L, S M$ versus $H$, and $S M$ versus $W$ ) allometric relations, $k$ exceeded 1.00 which means a positive allometry for these pairs of variables. Higher $k$ values were obtained for relation involving the weight. No significant relations were obtained for the circle or ellipse indices in relation to the length. For $H$ to $L$ allometric relation, classical and piecewise regressions had similar goodness of fit (AIC scores close to -2360$)$. For $S M$ to $L$ allometric relation, AIC score with classical model amounted to 859, whereas it is established to 854 with piecewise regression, this second modeling was considered to be better adjusted to our data for this ratio. The results of these two piecewise regressions ( $H$ to $L, S M$ to $L$ ) showed breakpoints corresponding, respectively, to $L=15.7 \mathrm{~mm}$ and $L=19.6 \mathrm{~mm}$.

\subsection{Spatial Allometry Patterns, Density, and Disease Effects.} For clams longer than $30 \mathrm{~mm}$, the shape was correctly summarized by the first three dimensions of the NPCA $(93.8 \%$ of the variance) described in Table 2, hereafter called Character 1, Character 2, and Character 3.

Heavy shells (regarding classical linear dimensions) with high values of width related to length were found in strata A, C, and S1. Those globular shells were associated with lowdensity levels (average 48 clams $\mathrm{m}^{-2}$ ) and high proportions of clams infected by BMD (average $12 \%$ of the sample) (see Figures 3 and 4). Besides, those two factors were significantly discriminated on the first axe which was characterized by the variables $S M / L, S M / H, W / L$ ratios, circle and reference ellipse lateral indices. 


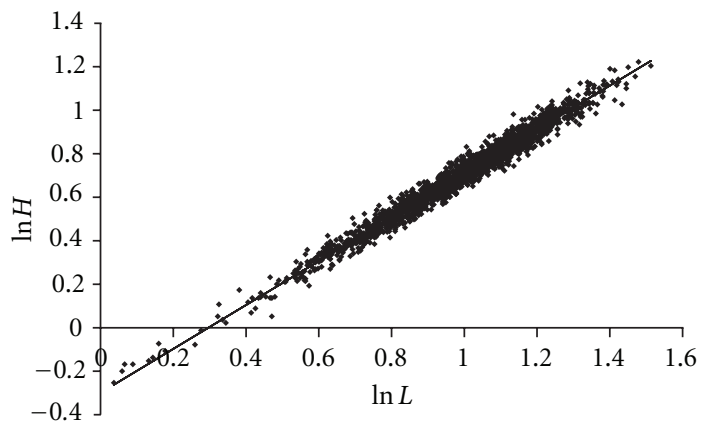

(a)

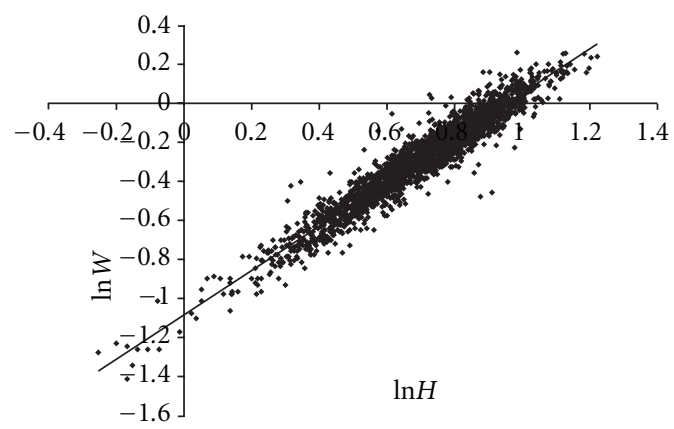

(c)

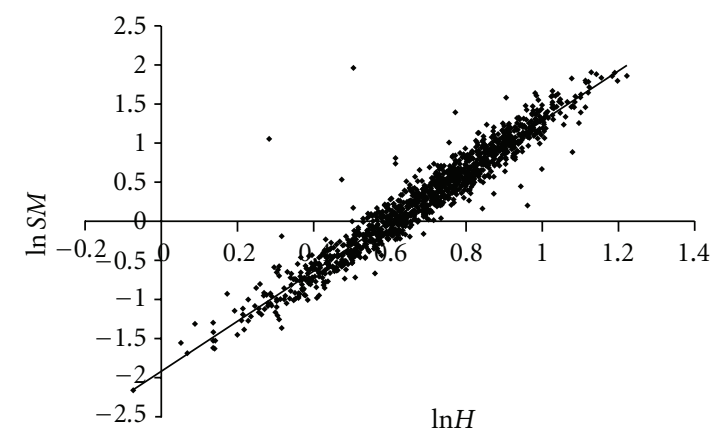

(e)

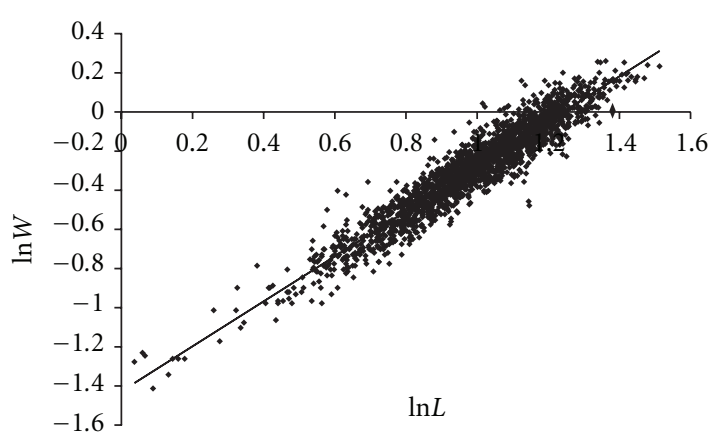

(b)

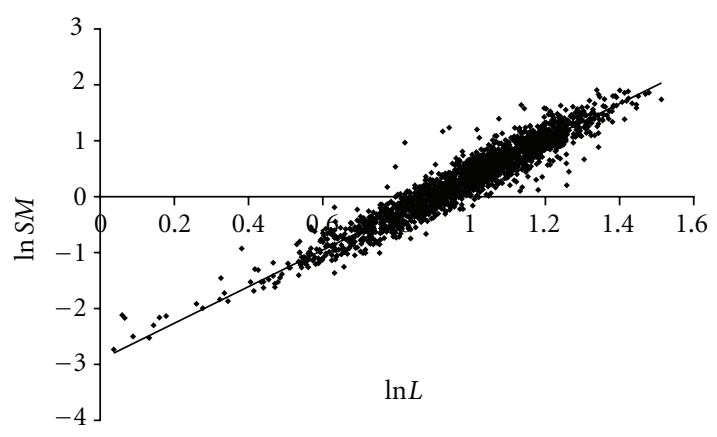

(d)

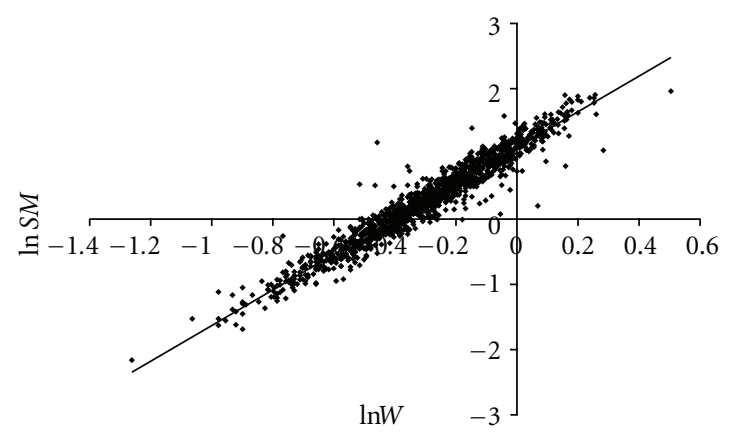

(f)

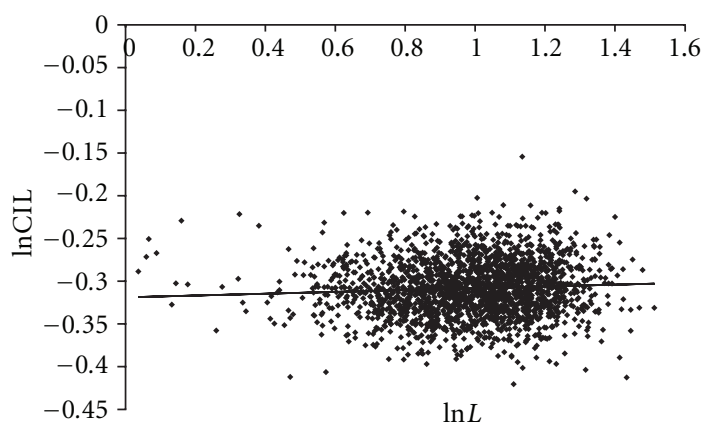

(g)

FIGURE 2: Allometric relations for pairs of parameters and shape descriptors (logarithmically transformed data). 
TABLE 2: NPCA synthetic descriptors.

\begin{tabular}{lll}
\hline $\begin{array}{l}\text { Selected principal } \\
\text { components }\end{array}$ & Description & Shape tendency \\
\hline Character1 & $\begin{array}{l}\text { Individuals presenting high values for } S M / L, S M / H, \\
W / L \text { ratios, high indices related to ventral circle and } \\
\text { reference ellipse } \\
L, H / L, \text { EIL, CIL and two of the weight ratios }(S M / H \\
\text { and } S M / W) \text { : the higher the indices of related mass and } \\
\text { length, the less the clam presents a round form (lateral } \\
\text { view) }\end{array}$ & $\begin{array}{l}\text { Heavy shells regarding linear measures and high values } \\
\text { of width related to length-globular individuals }\end{array}$ \\
& $\begin{array}{l}\text { Shells with high } H / L \text { ratio and lateral indices, by } \\
\text { opposition to low } W / L \text { and } W / H \text { ratios }\end{array}$ & $\begin{array}{l}\text { Round shells (lateral view) and little width related to } \\
\text { length and height }\end{array}$ \\
\hline
\end{tabular}

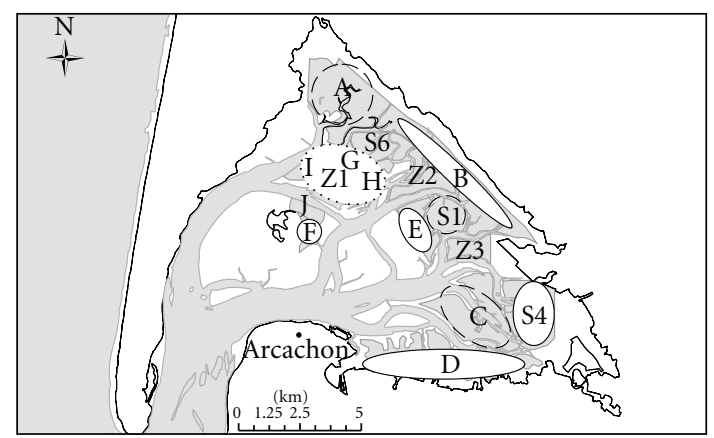
(-) Relative heavy and globular clams associated with high BMD and low denisty
$\bigcirc$ Relative light clams with D case (particularly round (front) clams)
$\because \cdots:$ Relative heavy and elongated clams

FIGURE 3: Spatial vizualisation of the allometry patterns related to density and disease.

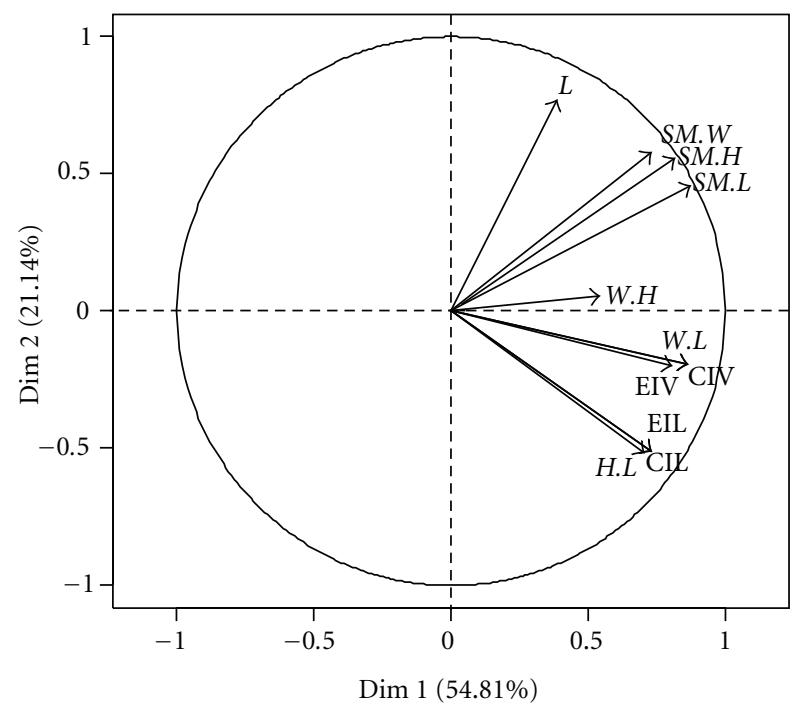

(a)

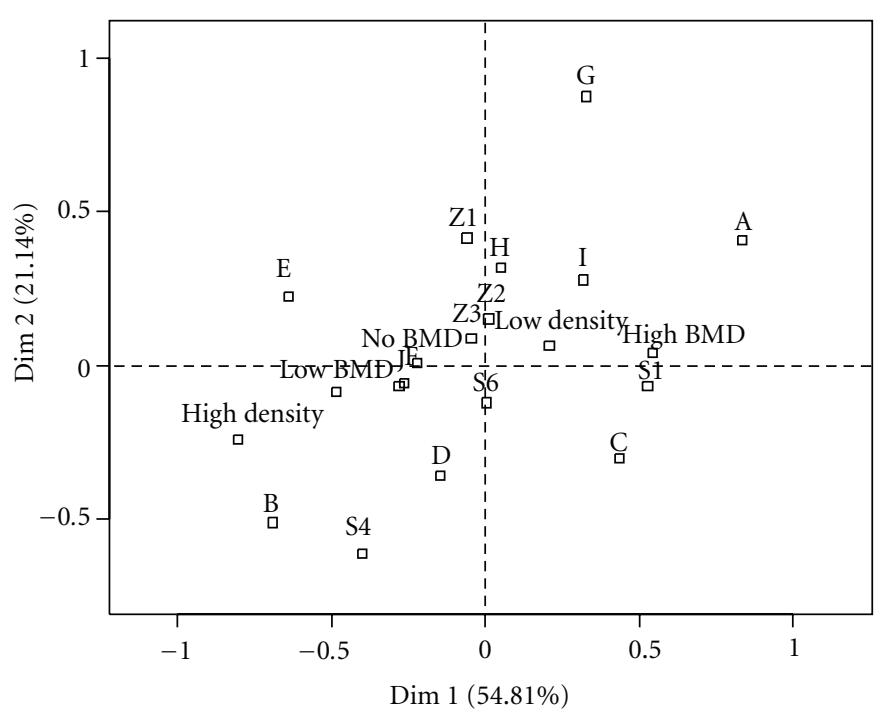

(b)

FIGURE 4: NPCA on morphometric variables (individuals and variables graphs) with strata, density, and BMD as supplementary factors. 
TABLE 3: Comparison of morphometric results with other sites including Europe.

\begin{tabular}{|c|c|c|c|}
\hline Site/Area & $\begin{array}{l}\text { Mean morphometrics } \\
\text { results }\end{array}$ & $\begin{array}{l}\text { Length (S. D.) indications of the } \\
\text { studied population }(\mathrm{mm})\end{array}$ & Sources \\
\hline \multirow{2}{*}{ Japan } & $\overline{H / L}$ from 0.70 to 0.75 & \multirow{2}{*}{ Range $10.8(0.60)$ to $11.5(0.63)$} & \multirow{2}{*}{$\begin{array}{l}\text { Deduced from Watanabe and Katayama } \\
{[23] \text {-Figure } 3}\end{array}$} \\
\hline & $\overline{W / L}$ from 0.40 to 0.45 & & \\
\hline \multirow{2}{*}{ China } & $\overline{H / L}=0.69$ & \multirow{2}{*}{ Mean Length 20.35 (1.35) } & \multirow{2}{*}{ Deduced from Fan et al. [33]—Table 1} \\
\hline & $\overline{W / L}=0.44$ & & \\
\hline \multirow{2}{*}{ Spain (bottom culture) } & $\bar{H} / \bar{L}$ from 0.58 to 0.73 & \multirow{2}{*}{ Range $13.7(0.26)$ to $26.6(0.43)$} & \multirow{2}{*}{$\begin{array}{l}\text { Deduced from Cigarría and Fernández } \\
{[18] \text {-Table } 1}\end{array}$} \\
\hline & $\bar{W} / \bar{L}$ from 0.41 to 0.48 & & \\
\hline \multirow[t]{2}{*}{ Tunisia } & $\bar{H} / \bar{L}=0.69$ & \multirow{2}{*}{ Mean Length 35.0 (3.82) } & \multirow{2}{*}{ Deduced from Ben Ouada et al. [30]—Table 1} \\
\hline & $\bar{W} / \bar{L}=0.44$ & & \\
\hline \multirow[t]{2}{*}{ Italy } & $\bar{H} / \bar{L}=0.71$ & \multirow{2}{*}{ Mean Length 39.2 (5.7) } & \multirow{2}{*}{ Deduced from Geri et al. [34]—Table 1} \\
\hline & $\bar{W} / \bar{L}=0.50$ & & \\
\hline \multirow{2}{*}{ France (Barfleur) } & $\overline{H / L}$ from 0.68 to 0.71 & \multirow{2}{*}{ Range 19 to 33} & \multirow{2}{*}{ Deduced from Gérard [7]_Figures 32 and 36} \\
\hline & $\overline{W / L}$ from 0.40 to 0.48 & & \\
\hline
\end{tabular}

Note: after having checked for valves symmetry on a subsample, the W/L ratio (obtained by TNPC system) for Arcachon was multiplied by two in order to allow for realistic comparison with published ratios.

Heavy shells (regarding classical linear dimensions) but associated to high values of lengths were found in strata $G$, $\mathrm{H}, \mathrm{Z1}$, and $\mathrm{Z3}$.

Those two types of strata differ from strata B, E, and S4 for which individuals presented low weight related to length, height, or width.

Stratum D was illustrated by circular shells (lateral view) and little width related to length and height by opposition to strata F, S1, and Z3.

Spatial visualization of those results revealed a typology defined by 3 main areas which differ in particular by their distance to the ocean connection (Figure 3 ).

\section{Discussion}

4.1. Shell Shape: Profile and Main Characteristics according to Some Populational Descriptors. This current study investigates the morphometric traits of Ruditapes philippinarum within Arcachon Bay using ratios classically employed for calcified structures. Observed values for those ratios (Table 1) establish that this population is characterized by relatively round $(H / L=0.75, \mathrm{CIL}=0.73)$ and globular shells $(W / L=0.28$, EIV $=0.95)$. Those results confirm the professional observations on the existence of a peculiar morphological pattern (so-called globular or "boudeuses" clams by French fishermen) which is described by a more compact form as usually observed.

Those conventional morphometric variables allow for comparison between the Arcachon Bay population and other ones from remote sites (deduced from $[7,18,23,30,33$, 34]). It emphasizes that shells are characterized by a much less elongated and more globular form than in other sites including Europe (Table 3) highlighting so a less favorable environment for the development of the clam and also individuals less attractive for economical point of view. These results are still consistent if we consider only the smallest individuals as Cigarría and Fernández [18], Watanabe and Katayama [23] did (data not shown).

Dependence of shell morphology on local environmental conditions has been indicated by Costa et al. [12] reminding inter alia the phenotypic plasticity in valve shape with a reference to the work of Kwon et al. [11] on transplantation results. They correspond more globally to the concept proposed by Lucas [8] in which ecological conditions seem to strongly influence both bivalves' morphology and physiology. The spatial patterns observed at the bay scale advocate for the existence of specific local environmental conditions that could be related for example to the hypsometric level or to continental input. Unfortunately in this present study, we couldn't take into account those kinds of factors.

Our study focuses on two factors that may affect the observed shape descriptors within the bay: i/density and ii/presence of an emergent disease, the BMD. Relationships among low density (below 100 clams $\mathrm{m}^{-2}$ ), absence or low presence of BMD (proportion of clams infected by BMD within the sample ranging from 0 to $3.7 \%$ ) and clams presenting high $S M / L, S M / H$, and $W / L$ ratios are highlighted using the observed values in Arcachon Bay.

The question of density dependence of the Manila clam's shell shape appears to have been considered in the literature but with no consensus. In our study, concomitance between high densities and propensity to be elongated is depicted. This is comparable to the results obtained by Cigarría and Fernández [18] in Eo Estuary (Spain) for this same species but under lowest densities conditions for Arcachon Bay

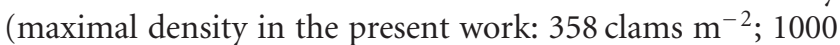
clams $\mathrm{m}^{-2}$ for Eo estuary). For the Spanish site, this height's density dependence was interpreted as a consequence of space competition since the height corresponds to the horizontal occupation in the sediment (because of the position of the buried clam). Space competition issue was also reported for Cerastoderma edule [35, 36]. Alumno-Bruscia et al. [37] describe as well an elongation of the shell for high population 
density for Mytilus edulis, while it is interesting to note that they raised the question of a consequence of a real physical interference, food depletion, or a combination of both. With respect to Manila clam, different observations have been made. Clam density was identified among other factors to impact the suitability of lagoon's areas (at local scale) for clam cultivation through a model-based approach [38]. For high densities conditions, Ohba [15] observed an increase of length proportionately less important than the ones in height and width. Bourne and Adkins [16] reported a common happening of stunted clams for wild populations and Mitchell [17] stated for Manila clam that density in the Canadian beach determines the maximum size they will grow before stunting occurs. Otherwise, a competition for space was also suggested between Ruditapes philippinarum and three species (Mactra veneriformis, Nihonotrypaea japonica, and Upogebia major) by Tamaki et al. [39]. For the Arcachon population, low density levels are associated with heavy and globular character. A common unfavorable environmental factor (see below) could be considered to explain these observations. Because the densities remain much lower than other studied sites, we can address in the same time the question of an environmental reason going beyond density strictly seen as spatial interference as suggested by some authors. A possible limitation of the maximum carrying capacity due to all the filter feeding species and not only within the Manila clam's population could be a hypothesis. On intraspecific competition issues to explain growth deficit, it would also have been interesting to consider the biomass. Insofar as we selected here the individuals above $30 \mathrm{~mm}$, we consider that the biomass and density are well correlated.

To the best of our knowledge, correlation between disease and morphology had not been studied. For the Arcachon population, relationships between high proportion of clams affected by BMD and globular form (associated to heavy clams regarding length and height) have been described. Recently highlighted by Dang et al. [19], this pathology affects the posterior adductor muscle and leads to a progressive calcification of this organ. Valve activity and clam mobility appear to be affected, including valves hermetic ability. Because causal relationship between the globular form and BMD has not been demonstrated, we can wonder if the disease could have impacted the globular form or if unfavorable environmental condition leading to specific shape patterns could have favored the affection development in specific site. The first hypothesis is supported by a significant discrimination of the BMD modalities on the first axe which is characterized by the variables $S M / L$, $S M / H, W / L$ ratios, circle and reference ellipse lateral indices. It implies that the disease would develop a sufficiently long time to modify the shell shape. So far, the only available information is that the smaller infected recorded clam is $26 \mathrm{~mm}$ long (de Montaudouin, personal communication). For the second hypothesis, no argument is available up to now. Both of them are in accordance with the description of a decrease of the condition index (for Arcachon Bay) associated to the BMD pathology [40]. It is also consistent with the highlighted correlation between $H / L$ and to a less extent $W / L$ with nutritional condition indices described by
Watanabe and Katayama [23]. More generally, the observed globularity is in accordance with phenotypic changes under "unfavorable" conditions described by several authors $[3,9$, $25]$.

Apart from density and disease effects, other factors have been proposed or demonstrated to impact the shell morphology. From an evolutionary point of view, defense against predator is considered as the most important function of the shell as reminded by Tokeshi et al. [41]. Considering different species of bivalves including a related species Ruditapes variegatus, these authors pointed out that the larger the shell, the more resistant the shell is regarding breakage by predators. For M. balthica in the North Sea, the hypothesis of a selective predation of the more globular shells has been proposed by Luttikhuizen et al. [42]. For avian predators, this form may mean a harder prey to swallow but also promotes a higher salt content which is according to Visser et al. [43] research, energetically costly to excrete. Those biological interpretations are applicable for fast predators but for slower ones, the capacity of moving away and burrowing deeper is considered as prevailing and is easier for flatter shells [42].

The main influence of predation on molluscan shell morphology has also been indicated by Watanabe and Katayama [23], but they attributed preferentially significant local differences in elongation and compactness indices to differences of nutritional conditions as explained above.

Other factors such as current velocity, water depth, or nature of the sediment have also been proposed for their influence on Venerids' shape [7, 44-46]. For Gérard [7], the nature of the sediment is of a great influence on the sharpness of the shell. For Tapes rhomboides, a related species, globular character was depicted in the Plymouth region (Great Brittany). Originally attributed by Holme [44] to an effect of pressure (related to water depth), this conclusion was challenged by Eagar [45] who focused on other physical conditions (muddy substrates and sheltered localizations). He made the physiological assumption that "obesity" could prevent the shell from sinking within the sediment and could provide stability. On other bivalves species (Tellina tenuis, Donax vittatus, Macoma balthica, and Cerastoderma edule), Trueman et al. [47] reported an effect of substrate of particle size and shell shape on the penetration of the bivalves' shells.

Up to now, those environmental factors are incompletely known for Arcachon Bay by comparison with other sites and should require further investigations.

\subsection{Allometric Patterns: Synthetic Descriptors of Main Interest} of Growth. For the first time, our study provides allometric data for the main exploited stock in France (see Table 1 and Figure 2). Allometric coefficient $(k)$ is ranging between 1 (isometry for $H$ to $L$ ) and 3 (positive allometry with higher coefficient for ratios taking into account the weight). Those values are consistent with other allometric patterns described for Ruditapes philippinarum and related species such as Ruditapes decussatus, Ruditapes variegatus, and Tapes rhomboides [7, 41, 48, 49]. In particular, considering that age is in turn reflected by the length like Eagar et al. [9] did, our results confirm that the globular character is more pronounced in ageing individuals. 
Both linear and piecewise regressions models fit correctly the data for $H$ to $L$ and $S M$ to $L$ relationships, despite the fact that the piecewise model appears to be better in the case of $S M$ to $L$. Both of them highlight discontinuities in the relative growth curves with marked breakpoints at length $15.7 \mathrm{~mm}$ and $19.6 \mathrm{~mm}$. After the growth becomes faster for directions other than length and clams tend to be globular. Katsanevakis et al. [28] estimated that those changes in growth trajectories during ontogeny were worth being taking into account since they can be linked to marked events in the life history or fast ecological changes. For Manila clam, the identified breakpoints correspond to the second year of life of the clam; they match with the supposed size of maturity for this species. According to Holland and Chew [50], sexual maturation begins at $5 \mathrm{~mm}$ and spawning at $20 \mathrm{~mm}$ for Manila clam.

For Venerupis senegalensis, it is interesting to note that Eagar [45] observed a second breakpoint interpreted as a shell-limiting process for $H$ to $L$ and $W$ to $L$ for length class plotted against length of shell. The physiological explanation proposed by this author was a weaker efficacy of muscles when respiratory and food-collecting capacity per unit tissue decrease while the length increases. Those results were obtained with mean ratios per length classes, ignoring the individual variability information.

Spatial variability is shown and three main morphological groups of adult clams are identified. For those clams, similar shell shape appears to be grouped in the proximate strata $\mathrm{G}, \mathrm{H}$, and $\mathrm{Z1}$; they could be seen as clams living in optimal conditions compared to the rest of the bay. The shape tendencies also appear to differ by their distance to the ocean connection (Figure 3). A high intertidal localization (involved in particular in the access time to food supply) could intervene but the necessary data were not considered in this work to address this point. This would be consistent with the observations of stunted clams especially in high intertidal areas and at higher clam densities done by Bourne and Adkins [16].

Morphometric investigations led by Ben Ouada et al. [30] on Ruditapes decussatus for sites along the Tunisian coast identified the existence of three phenotypes (globular, slender, truncated) and established a high polymorphism not only at between-population but also at within-population scales. This high variability within population was also genetically demonstrated $[51,52]$. Nevertheless, Luttikhuizen et al. [42] established that shell shape variation was not randomly distributed over sites for Macoma balthica, and Costa et al. [12] indicated that "contribution of local adaptation to the morphological differentiation of population of clam is still poorly studied phenomenon."

4.3. Regulation Considerations. Currently four conservation measures are applied to regulate the fishing activity (number of licenses, minimum legal harvest size, fishing period, and no-take zones). Among those, the minimum legal harvest size is the only measure defined by European legislation; in practice applicable to the whole catches in Europe. Manila clam in Arcachon Bay presents a growth deficiency above $32 \mathrm{~mm}$ [20] and the present study reveals a different morphology for the shell shape compared to other sites with a propensity to be globular. These characteristics are both driven by environmental factors and exploitation; do they reflect a situation of stress for this species or adaptation? Can they challenge the minimum legal harvest size for the benefit of a local one more adapted to this situation?

\section{Conflict of Interests}

All authors declare no conflict of interests.

\section{Acknowledgments}

The authors are grateful to Xavier de Montaudouin and Cindy Binias for supplying data on BMD, to Muriel Lissardy for providing localization map. They also wish to thank the anonymous reviewer and Dr. Robert A. Patzner for their constructive comments on the paper. University of Pau \& Pays de l'Adour (UPPA-ED 211) provided financial support to N. Caill-Milly to attend the 5th EUROLAG/25-30 July 2011 in Aveiro (Portugal).

\section{References}

[1] E. Gosling, Bivalve Molluscs: Biology, Ecology and Culture, Fishing News Books, Oxford, UK, 2003.

[2] R. Seed, "Shell growth and form in the Bivalvia," in Skeletal Growth of Aquatic Organisms, D. C. Rhoads and R. A. Lutz, Eds., pp. 23-67, Plenum Press, New York, NY, USA, 1980.

[3] S. Ohba, "Ecological studies in the natural population of a clam, Tapes japonica, with special reference to seasonal variations in the size and structure of the population and to individual growth," Biological Journal of Okayama University, vol. 5, pp. 13-42, 1959.

[4] R. Seed, "Factors influencing shell shape in the mussel, Mytilus edulis L," Journal of the Marine Biological Association of the United Kingdom, vol. 48, pp. 561-584, 1968.

[5] G. D. Rosenberg, Patterned growth of the bivalve Chione undatella (Sowerby) relative to the environment [Dissertation thesis], Departement of Geology, University of California, 1972.

[6] R. A. Brown, R. Seed, and R. J. O. O'Connor, "A comparison of relative growth in Cerastoderma (= Cardium) edule, Modiolus modiolus and Mytilus edulis (Mollusca: Bivalvia)," Journal of the Zoological Society of London, vol. 179, pp. 297-315, 1976.

[7] A. Gérard, Recherches sur la variabilité de diverses populations de Ruditapes decussatus et Ruditapes philippinarum (Veneridae, Bivalvia) [Dissertation thesis], Université de Bretagne Occidentale, 1978 .

[8] A. Lucas, "Adaptations écophysiologiques des bivalves aux conditions de culture," Bulletin de la Société d'Ecophysiologie, vol. 6, pp. 27-35, 1981.

[9] R. M. C. Eagar, N. M. Stone, and P. A. Dickson, "Correlations between shape, weight and thickness of shell in four populations of Venerupis rhomboides (Pennant)," Journal of Molluscan Studies, vol. 50, pp. 19-38, 1984.

[10] H. P. Stirling and I. Okumus, "Growth, mortality and shell morphology of cultivated mussel (Mytilus edulis) stocks cross planted between two Scottish sea lochs," Marine Biology, vol. 119, no. 1, pp. 115-124, 1994.

[11] J. Y. Kwon, J. W. Park, Y. H. Lee, Y. K. Hong, and Y. J. Chang, "Morphological variation and genetic relationship among 
populations of shortnecked clam Ruditapes philippinarum collected from different habitats," Journal of Fisheries Science and Technology, vol. 2, pp. 98-104, 1999.

[12] C. Costa, J. Aguzzi, P. Menesatti, F. Antonucci, V. Rimatori, and M. Mattoccia, "Shape analysis of different populations of clams in relation to their geographical structure," Journal of Zoology, vol. 276, no. 1, pp. 71-80, 2008.

[13] A. J. S. Hawkins and B. L. Bayne, "Physiological interrelations and the regulation of production," in The Mussel Mytilus: Ecology, Physiology, Genetics and Culture, E. M. Gosling, Ed., pp. 171-222, Elsevier Science, Amsterdam, The Netherlands, 1992.

[14] C. M. Yonge and J. I. Campbell, "On the heteromyarian conditions in the Bivalvia with special reference to Dreissena polymorpha and certain Mytilacea," Transactions of the Royal Society of Edinburgh, vol. 68, pp. 21-43, 1968.

[15] S. Ohba, "Effect of population density on mortality and growth in an experimental culture of bivalve, Venerupis semidecussata," Biological Journal of Okayama University, vol. 112, pp. 169-173, 1956.

[16] N. Bourne N and B. Adkins, "Savary Island clam study," Canadian Manuscript Report of Fisheries and Aquatic Sciences, pp. 69-95, 1848.

[17] D. Mitchell, "Effect of seed density on Manila clam growth and production at a British Columbia clam farm," Bulletin of Aquaculture Association of Canada, vol. 92, no. 4, pp. 29-32, 1992.

[18] J. Cigarría and J. Fernández, "Manila clam (Ruditapes philippinarum) culture in oyster bags: influence of density on survival, growth and biometric relationships," Journal of the Marine Biological Association of the United Kingdom, vol. 78, no. 2, pp. 551-560, 1998.

[19] C. Dang, X. De Montaudouin, P. Gonzalez, N. MesmerDudons, and N. Caill-Milly, "Brown muscle disease (BMD), an emergent pathology affecting Manila clam Ruditapes philippinarum in Arcachon Bay (SW France)," Diseases of Aquatic Organisms, vol. 80, no. 3, pp. 219-228, 2008.

[20] C. Dang, Dynamique des populations de palourdes japonaises (Ruditapes philippinarum) dans le bassin d'Arcachon, conséquences sur la gestion des populations exploitées [dissertation thesis], University of Bordeaux I, Bordeaux, France, 2009.

[21] M. Plus, D. Maurer, J. Y. Stanisière, and F. Dumas, "Caractérisation des composants hydrodynamiques d'une lagune mésotidale, le bassin d'Arcachon," Rapport Ifremer, RST/ LER/AR/06. 007, 2006.

[22] D. S. Mc Lusky and M. Elliott, The Estuarine EcosystemEcology, Threats and Management, Oxford University Press, New York, NY, USA, 3rd edition, 2004.

[23] S. Watanabe and S. Katayama, "Relationships among shell shape, shell growth rate, and nutritional condition in the manila clam (Ruditapes philippinarum) in Japan," Journal of Shellfish Research, vol. 29, no. 2, pp. 353-359, 2010.

[24] N. I. Selin, "Shell form, growth and life span of Astarte arctica and A. borealis (Mollusca: Bivalvia) from the subtidal zone of northeastern Sakhalin," Russian Journal of Marine Biology, vol. 33, no. 4, pp. 232-237, 2007.

[25] I. Hamai, "A study of one case in which environmental conditions produce different types in Meretrix meretrix (L.)," Science Reports of Tôhoku University, vol. 10, pp. 485-498, 1935.

[26] J. S. Huxley, Problems of Relative Growth, Methuen, London, UK, 1932.

[27] J. D. Toms and M. L. Lesperance, "Piecewise regression: a tool for identifying ecological thresholds," Ecology, vol. 84, no. 8, pp. 2034-2041, 2003.
[28] S. Katsanevakis, M. Thessalou-Legaki, C. Karlou-Riga, E. Lefkaditou, E. Dimitriou, and G. Verriopoulos, "Informationtheory approach to allometric growth of marine organisms," Marine Biology, vol. 151, no. 3, pp. 949-959, 2007.

[29] Y. Sakamo, M. Ishiguro, and G. Kitagawa, Akaike Information Criterion Statistics, D. Reidel, 1986.

[30] H. Ben Ouada, M. N. Medhioub, A. Medhioub, H. Jammoussi, and M. Beji, "Variabilité morphométrique de la palourde Ruditapes decussatus (Linné, 1758) le long des côtes tunisiennes," Haliotis, vol. 27, pp. 43-55, 1998.

[31] D. Wildish, H. Akagi, B. Hatt et al., "Population analysis of horse mussels of the inner Bay of Fundy based on estimated age, valve allometry and biomass," Canadian Technical Report of Fisheries and Aquatic Sciences, Vol. 2257, 1998.

[32] D. L. Sonderegger, H. Wang, W. H. Clements, and B. R. Noon, "Research communications research communications Using SiZer to detect thresholds in ecological data," Frontiers in Ecology and the Environment, vol. 7, no. 4, pp. 190-195, 2009.

[33] D. Fan, A. Zhang, Z. Yang, and X. Sun, "Observations on shell growth and morphology of the bivalve Ruditapes philippinarum," Chinese Journal of Oceanology and Limnology, vol. 25, no. 3, pp. 322-329, 2007.

[34] G. Geri, G. Parisi, P. Lupi et al., "Caratteristiche corporee in due specie di vongole [Tapes decussatus L. e. Tapes semidecussatus (Reeve] di taglia commercial," Zootecnica e Nutrizione Animale, vol. 22, pp. 103-118, 1996 (Italian).

[35] K. T. Jensen, "The presence of the bivalve Cerastoderma edule affects migration, survival and reproduction of the amphipod Corophium volutator," Marine Ecology Progress Series, vol. 25, pp. 269-277, 1985.

[36] X. De Montaudouin and G. Bachelet, "Experimental evidence of complex interactions between biotic and abiotic factors in the dynamics of an intertidal population of the bivalve Cerastoderma edule," Oceanologica Acta, vol. 19, no. 3-4, pp. 449-463, 1996.

[37] M. Alunno-Bruscia, E. Bourget, and M. Fréchette, "Shell allometry and length-mass-density relationship for Mytilus edulis in an experimental food-regulated situation," Marine Ecology Progress Series, vol. 219, pp. 177-188, 2001.

[38] C. M. Spillman, D. P. Hamilton, and J. Imberger, "Management strategies to optimise sustainable clam (Tapes philippinarum) harvests in Barbamarco Lagoon, Italy," Estuarine, Coastal and Shelf Science, vol. 81, no. 2, pp. 267-278, 2009.

[39] A. Tamaki, A. Nakaoka, H. Maekawa, and F. Yamada, "Spatial partitioning between species of the phytoplankton-feeding guild on an estuarine intertidal sand flat and its implication on habitat carrying capacity," Estuarine, Coastal and Shelf Science, vol. 78, no. 4, pp. 727-738, 2008.

[40] C. Dang and X. DeMontaudouin, "Brown muscle disease and Manila clam Ruditapes philippinarum dynamics in Arcachon Bay, France," Journal of Shellfish Research, vol. 28, no. 2, pp. 355-362, 2009.

[41] M. Tokeshi, N. Ota, and T. Kawai, "A comparative study of morphometry in shell-bearing molluscs," Journal of Zoology, vol. 251, no. 1, pp. 31-38, 2000.

[42] P. C. Luttikhuizen, J. Drent, W. Van Delden, and T. Piersma, "Spatially structured genetic variation in a broadcast spawning bivalve: quantitative vs. molecular traits," Journal of Evolutionary Biology, vol. 16, no. 2, pp. 260-272, 2003.

[43] G. H. Visser, A. Dekinga, B. Achterkamp, and T. Piersma, "Ingested water equilibrates isotopically with the body water pool of a shorebird with unrivaled water fluxes," American Journal of Physiology, vol. 279, no. 5, pp. R1795-R1804, 2000. 
[44] N. A. Holme A, "Shell form in Venerupis rhomboides (Pennant)," Journal of the Marine Biological Association of the United Kingdom, vol. 41, pp. 705-722, 1961.

[45] R. M. C. Eagar, "Shape and function of the shell: a comparison of some living and fossil bivalve mollusks," Biological Reviews of the Cambridge Philosophical Society, Part II, vol. 53, pp. 169210, 1978.

[46] J. Kakino, "Relationship between growth of Japanese little neck clam Ruditapes philippinarum and current velocity on Banzu tidal flat, Tokyo Bay," Bulletin of Chiba Prefectural Fisheries Experimental Station, 1996 (Japanese).

[47] E. R. Trueman, A. R. Brand, and P. Davis, "The effect of substrate and shell shape on the burrowing of some common bivalves," Proceedings of the Malacologica Society of London, vol. 37, pp. 97-109, 1966.

[48] F. Laruelle, J. Guillou, and Y. M. Paulet, "Reproductive pattern of the clams, Ruditapes decussatus and R. philippinarum on intertidal flats in Brittany," Journal of the Marine Biological Association of the United Kingdom, vol. 74, no. 2, pp. 351-366, 1994.

[49] M. B. Gaspar, M. N. Santos, P. Vasconcelos, and C. C. Monteiro, "Shell morphometric relationships of the most common bivalve species (Mollusca: Bivalvia) of the Algarve coast (southern Portugal)," Hydrobiologia, vol. 477, pp. 73-80, 2002.

[50] D. A. Holland and K. K. Chew, "Reproductive cycle of the Manila clam (Venerupis japonica) from Hood Canal, Washington," Proceedings of the National Shell-Fisheries Association, vol. 64, pp. 53-58, 1974.

[51] D. Moraga, Polymorphisme enzymatique de populations naturelles et expérimentales de la palourde européenne Ruditapes decussatus (L.) (Veneridae, Bivalvia) [dissertation thesis], Université de Bretagne Occidentale, 1984.

[52] P. Jarne, P. Berrebi, and O. Guélorget, "Variabilité génétique et morphométrique de cinq populations de la palourde Ruditapes decussatus," Oceanologia Acta, vol. 11, pp. 401-407, 1988. 

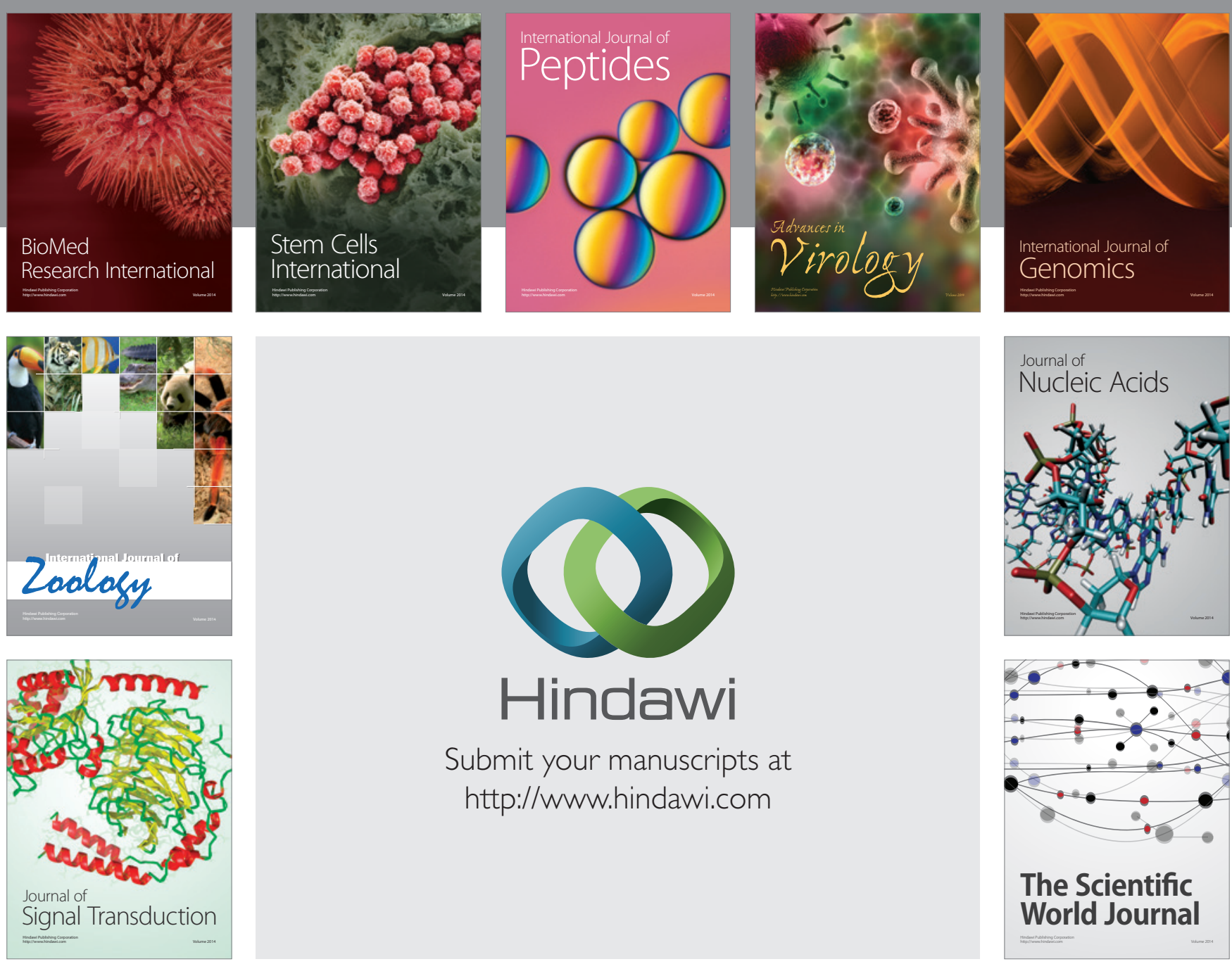

Submit your manuscripts at

http://www.hindawi.com
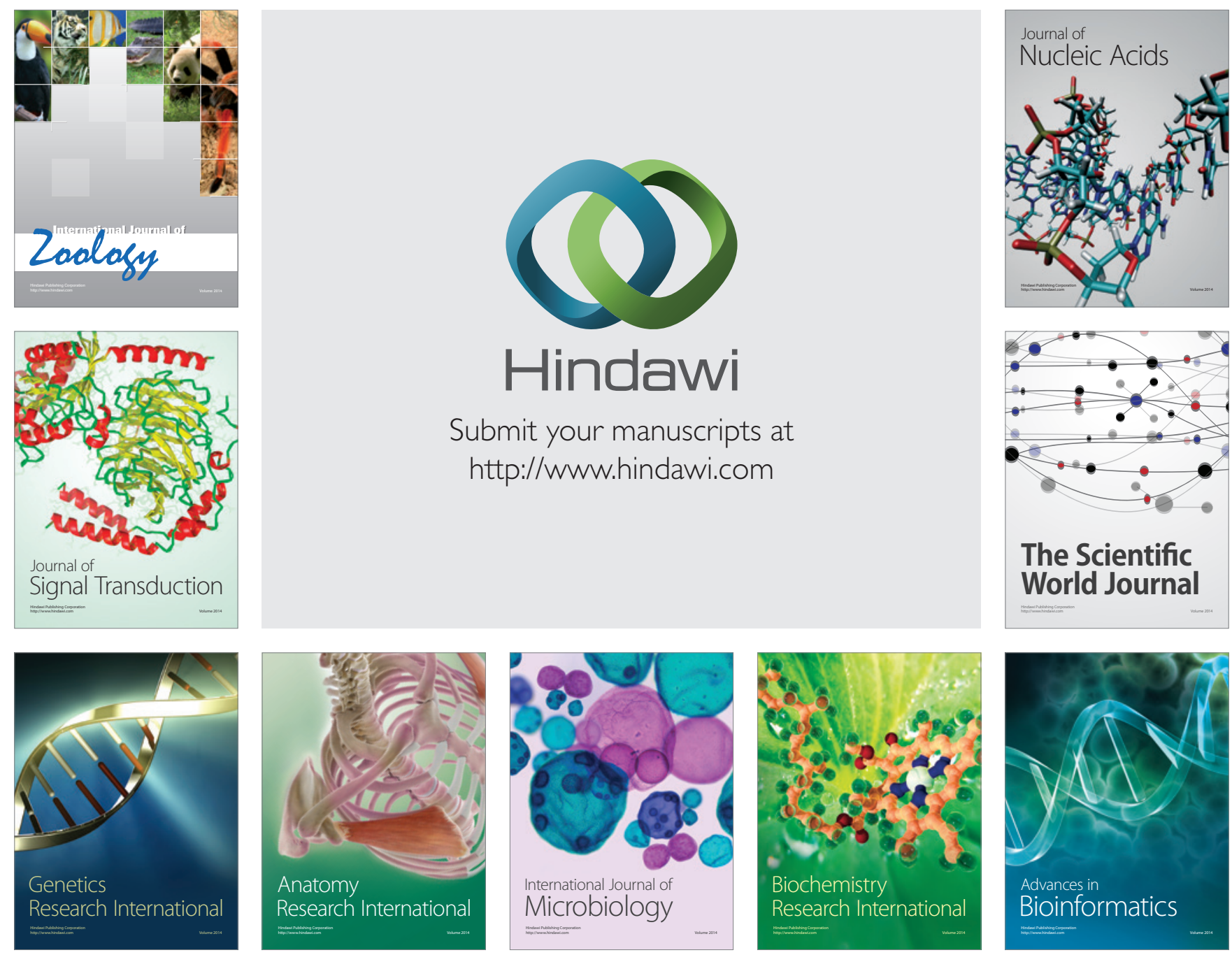

The Scientific World Journal
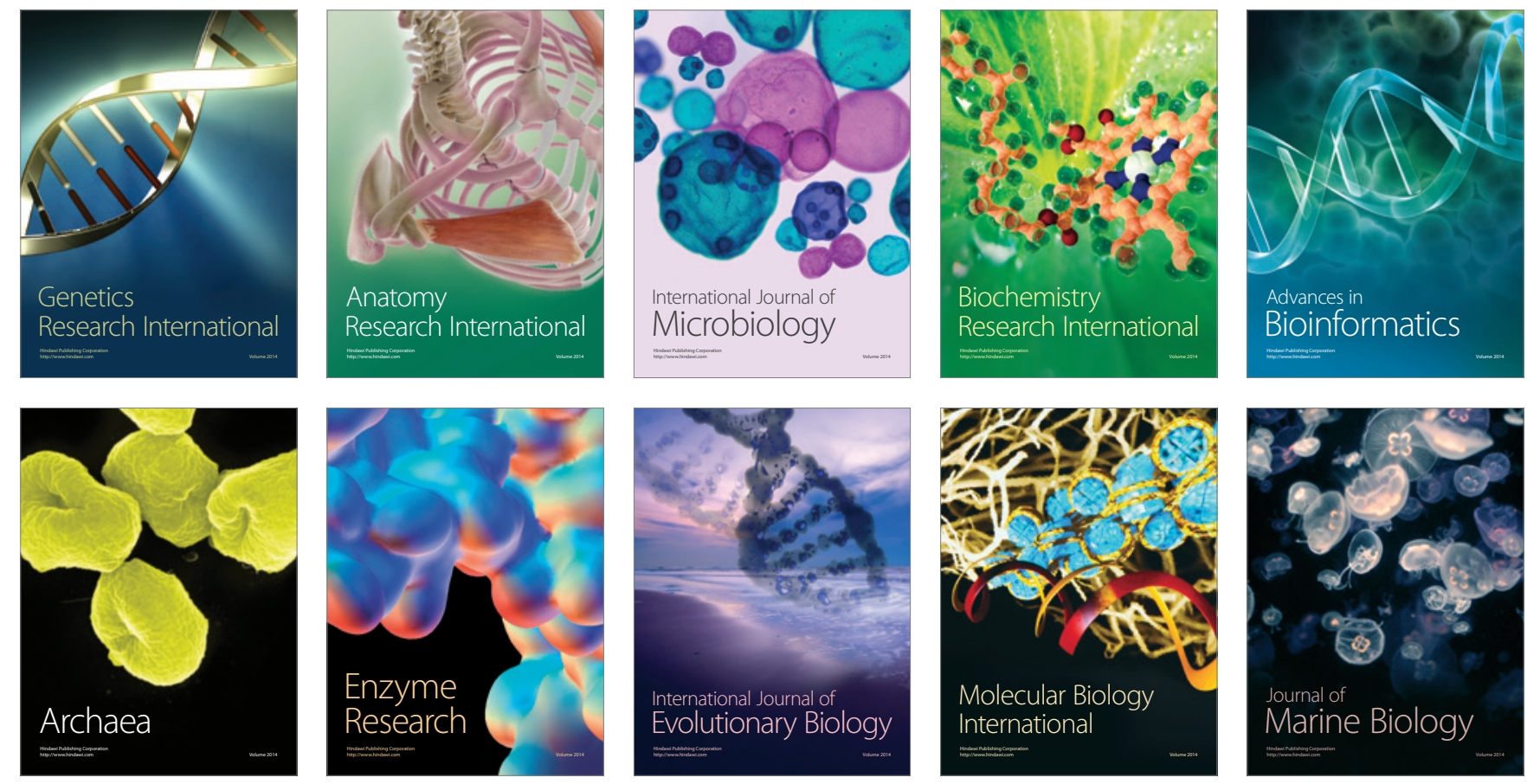